\title{
EFFECTIVENESS OF BRUSH-FINISHER IN CALCIUM HYDROXIDE REMOVAL FROM ROOT CANAL SYSTEM
}

\author{
Agata Koprowicz, Piotr Koprowicz \\ Department of Endodontics, Medical University of Lodz, Poland
}

\begin{abstract}
INTRODUCTION: It is very important to remove all intra-canal dressing placed between endodontic visits. The most common canal dressing is calcium hydroxide. Apart from its well-known benefits, calcium hydroxide is considered difficult to be completely removed from root canal system. In the literature, in an assessment of the effect of material removal from root canals, superiority of some instruments over the other are reported. Овјестіves: The aim of the study was to analyze the impact of Brush-Finisher on removing an intra-canal dressing in different root canal widths.

MATERIAL AND Methods: The study was performed using extracted single-rooted teeth, which were prepared to standardize all samples and divided into 2 groups, including large canals (LC, $n=8$ ) and narrow canals (NC, $n=8$ ) groups. As a control group of narrow and wide canals, a syringe with an endodontic needle was used (LC, $n=8$ and NC, $n=8$ ). Calcium hydroxide paste was placed into the canals. After 2 weeks, cleaning procedure was performed using $2 \% \mathrm{NaOCl}$ and a Brush-Finisher. After agitation of the rinsing solution, radiographs were taken in bucco-lingual and mesio-distal projections. Then, all radiographs were uploaded to graphic software, and the roots were divided into 3 parts: apical, middle, and coronal, and a crisscross pattern was carried out. Every square field located along the course of canal was calculated and evaluated in terms of the absence or presence of canal dressing. $P$-value of $<0.05$ was assumed statistically significant. For comparison of individual proportions, $\mathrm{N}-1 \chi^{2}$ test was used, while Marascuilo procedure was applied to evaluate significance between particular comparison of pairs.

RESUlTS: Significant difference between efficacy of $\mathrm{Ca}(\mathrm{OH})_{2}$ removal was observed comparing middle and coronal level in LC group (0.077) as well as between apical and middle level (0.106) and coronal and middle level (0.082) in NC group.

Conclusions: Activation of irrigation with the Brush-Finisher was more beneficial in removing $\mathrm{Ca}(\mathrm{OH})_{2}$ in narrow rather than large canals. Cleaning was less efficient in middle levels of both groups.
\end{abstract}

KEY wORDs: Brush-Finisher, calcium hydroxide, digital radiology, rinsing activating.

J Stoma 2021; 74, 2: 70-75

DOI: https://doi.org/10.5114/jos.2021.106261

\section{INTRODUCTION}

The development of modern endodontics has brought to the dental market new equipment for root canal preparation. It concerns both, mechanical and chemi- cal stage of canal preparation. A variety of instruments for rinsing activation are available, including ultrasonic and sonic devices, flexible micro-brushes, innovative files, and lasers [1, 2]. Recently, MedicNRG (Kibbutz Afikim, Israel) has introduced a product called "Gentle-

\section{JOURNAL OF} STOMATOLOGY CZASOPISMO STOMATOLOGICZNE

AdDress for Correspondence: Dr. Agata Koprowicz,

Department of Endodontics, Medical University of Lodz, 251 Pomorska Str., 92-213 Lodz, Poland, e-mail: agata.koprowicz@umed.lodz.pl 
file", which is an endodontic rotary system (Figure 1). It consists of a wireless micro-motor, a disposable head, and a set of steel files. An inconspicuous and very light micro-motor achieves the rotation speed up to $6500 \mathrm{rpm}$ and torque of $90 \mathrm{~g} / \mathrm{cm}$. All instruments from the set are allowed to be used during rinsing activation [3]. Moreover, there is an additional instrument in the kit, Gentlefile brush, called "Brush-Finisher" (Figure 2), consisting of seven steel filaments rolled around its axis. According to the manufacturer's instructions, it mainly serves to activate rinsing agents. Brush-Finisher is suitable for cleaning canal walls during endodontic re-treatment or root canal preparation to perform a prosthetic core and postcore restorations. There is still little data in the specialized literature on the use of the Gentlefile system in the root canal treatment. However, Hristov and Gateva [4] in their work demonstrated superiority of Gentlefile in disinfection of root canals in immature permanent teeth.

\section{OBJECTIVES}

In this study, the Brush-Finisher was used to agitate rinsing solution for calcium hydroxide removal, and the aim was to compare its performance on different canal widths.

\section{MATERIAL AND METHODS}

The ethical approval for this experimental study was given by the Bioethical Committee of the Medical University of Lodz (RNN/3988/19/KE of December 12 $\left.2^{\text {th }}, 2019\right)$. One hundred and fifty single-rooted extracted teeth obtained from private orthodontic dental clinics were radiographed to select those with single canals, curved up to 10 degrees (according to Schneider's method), without any canal fillings (gutta-percha, sealers, or canal dressing), calcifications, or root resorption. The samples were stored in a $10 \%$ buffered formalin solution until use. Crowns were removed by using a diamond disk to provide roots measuring of $17 \mathrm{~mm}( \pm 1 \mathrm{~mm})$ in length. According to the radiographs taken in two projections and apical foramen measurements performed with hand files, two groups of narrow and wide root canals were created (narrow canals, NC, $n=8$, and large canals, LC, $n=8$ ). If the first used hand file (IAF, initial apical file) larger than number 30 (i.e., $0.35 \mathrm{~mm}$ and more) wedged at the apical foramen, the canal was classified into the large root canal group (LC group). The middle and coronal part of the file had to be loose at the same time. ProTaper Next file number X3 (0.30 mm in size and 7.5\% taper; Dentsply, Ballaigues, Switzerland) was introduced loosely (without shaping) up to the apical foramen to remove residual parts of the pulp and confirm accurate classification related to the canal width.

The narrow canal group included canals with size less than $0.15 \mathrm{~mm}$ (based on IAF size). Narrow canals were

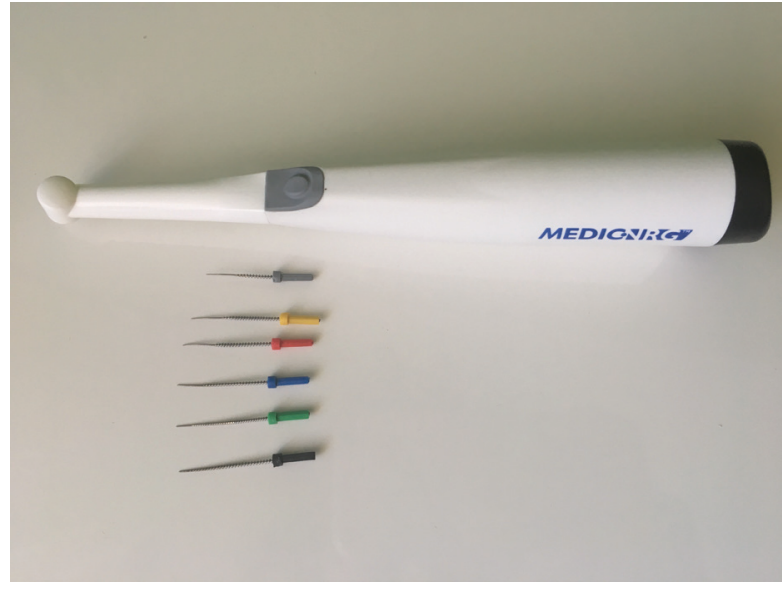

FIGURE 1. Gentlefile system: hand-piece and set of files

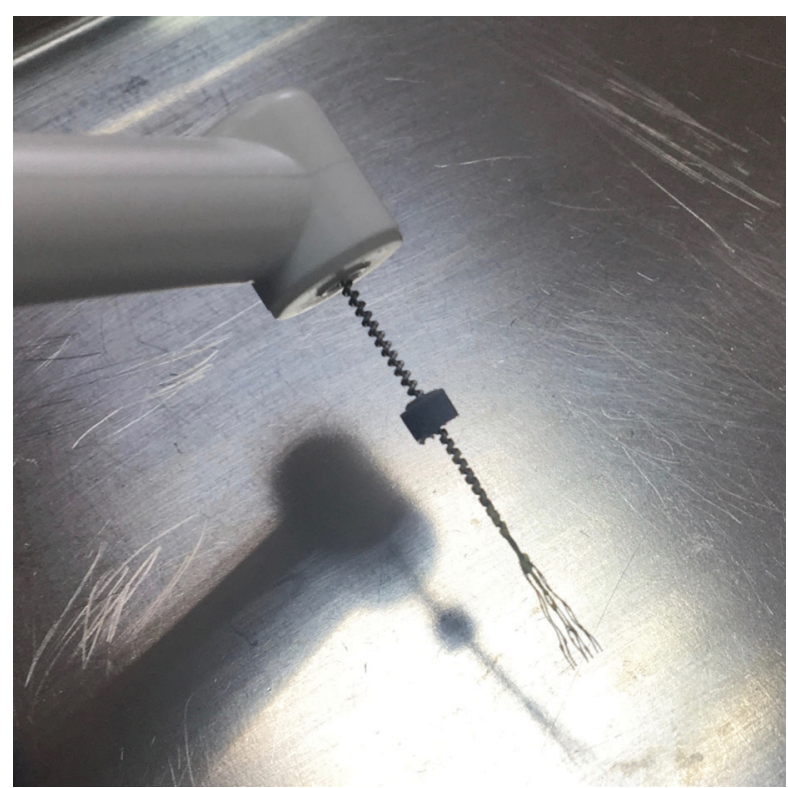

FIGURE 2. Gentlefile-brush (Brush-Finisher)

mechanically prepared up to the anatomical foramen in a sequence with C-pilot (10.02, VDW, Frankfurt, Germany), path files of 13.02 and 16.02 (Dentsply, Ballaigues, Switzerland), and ProTaper Next files number X1 and $\mathrm{X} 2(0.25 \mathrm{~mm}$ in size and 6\% taper). At the level of anatomical foramen, the final dimension of large and narrow canals differed from each other at least $0.1 \mathrm{~mm}$ or more. After abundant irrigation using $2 \% \mathrm{NaOCl}(5 \mathrm{ml}$, chloraxid 2\%, Cerkamed Medical Co., Stalowa Wola, Poland) and 17\% EDTA (5 ml, endo-solution, Cerkamed Medical Co., Stalowa Wola, Poland), all canals were dried and filled up with calcium hydroxide paste with iodoform (calcipast J, Cerkamed Medical Co., Stalowa Wola, Poland) using an applicator (placed at $1 \mathrm{~mm}$ short of the apical foramen and withdrawn during material filling) and the cavities were temporarily closed. Subsequently, each sample was placed in a silicone model to obtain two radiographs in the bucco-lingual and mesio-distal projection (GENDEX expertDC, $65 \mathrm{kV}$, 


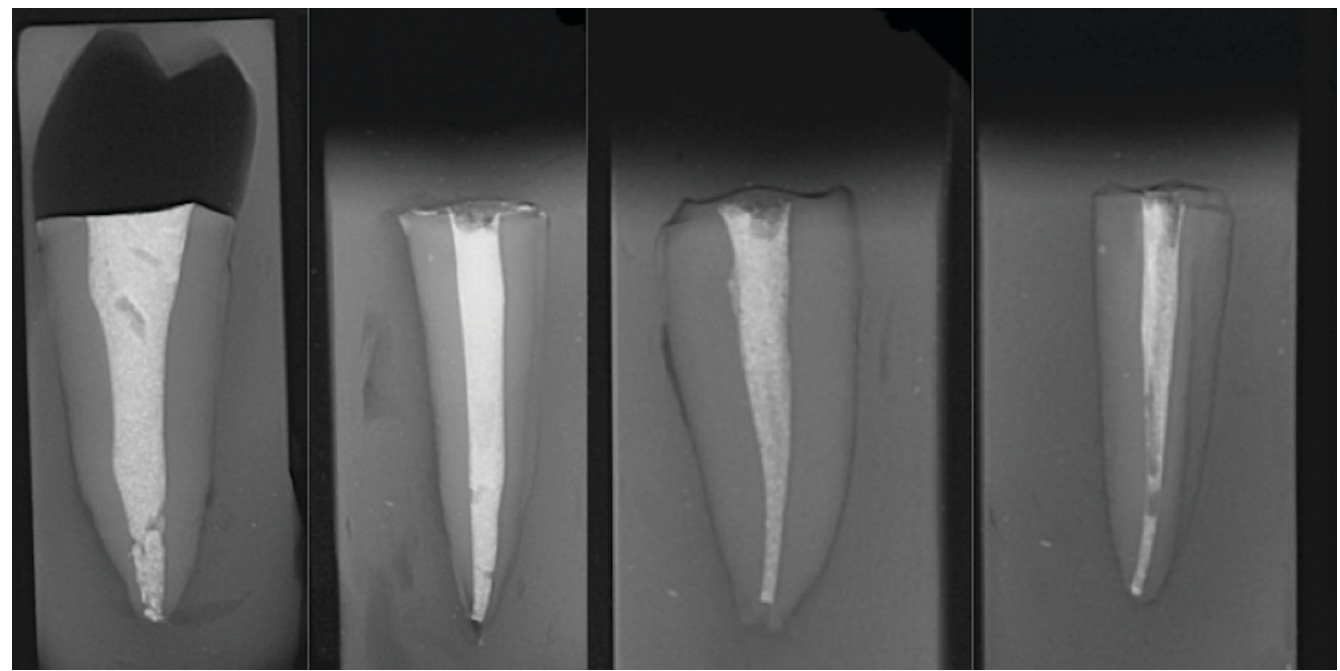

FIGURE 3. Example of wide and narrow canals filled with calcium hydroxide with iodoform (bucco-lingual and mesiodistal projection)

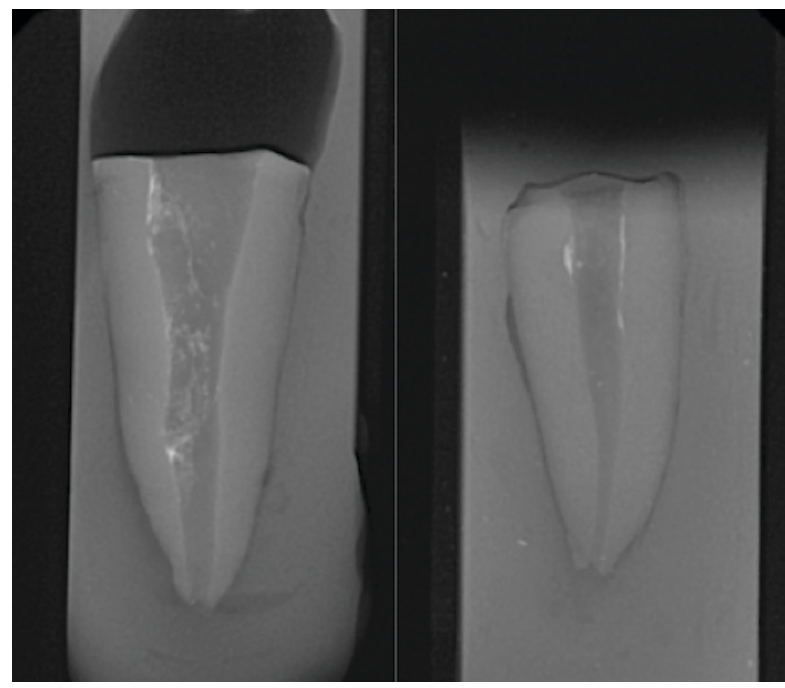

FIGURE 4. Wide and narrow canals after intra-canal dressing removal (bucco-lingual projection)

$7 \mathrm{~mA}, 0.250 \mathrm{~s}, \mathrm{KaVo}$, Brea, USA). If there was any void noticed in the canal filling, the procedure was repeated until sealing was acceptable (Figure 3 ). All samples were stored in an incubator at $37^{\circ} \mathrm{C}$ and $100 \%$ humidity for 14 days. After the procedure, the intra-canal dressing was removed.

Firstly, canal dressings were removed from the LC group and then from the NC group. The procedure was conducted by one operator according to the manufacturer's recommendations. In both groups, one irrigating solution of the same volume, i.e., $5 \mathrm{ml}$ of $2 \% \mathrm{NaOCl}$, was used. The needle of the syringe was inserted into the canal orifice, and the rinsing solution was agitated by the Brush-Finisher. It was performed by rotating and pecking motions up to the working length for approximately 2 minutes ( \pm 15 seconds), until the whole volume of rinse (5 ml) was finished. Every 15-20 seconds of activation, a short break was taken and the Brush-Finisher was cleaned from the dressing with abundant water irrigation and gauze. As a control group of narrow and wide canals, a $5 \mathrm{ml}$ Luer-lock syringe with an endodontic needle (with lateral foramen and size of $0.3 \mathrm{~mm}$ $\times 25 \mathrm{~mm}$, Endo-Top, Cerkamed Medical Co., Stalowa Wola, Poland) was used (LC, $n=8$ and NC, $n=8$ ). Each tooth sample was coated entirely with a silicone material (panzer putty) and inserted into a special handle to protect it from apical extrusion of the dressing and operator's impact on the irrigation procedure. After removal of the dressing (Figure 4), the same two-projection radiographs were repeated using a platform, which ensured the same radiological position. Subsequently, the images were uploaded into a graphic software (GIMP 2.8.22), and the root canals were divided into three parts, such as apical, middle, and coronal. To make the image more legible for the operator's analysis, graphic tools were applied to mark the canal space, circumscribe, and excise, removing the view of the root structures. Then, a crisscross pattern $(0.25 \mathrm{~mm} \times 0.25 \mathrm{~mm})$ was carried out on this excised canal image. Each square located along the course of the canal was counted and evaluated by the same operator twice, with 2 weeks inter$\mathrm{val}$, for the presence (in the amount of $100 \%, 75 \%, 50 \%$, and $25 \%$ of space) or absence of intra-canal dressing ( $0 \%$ - the whole square free from dressing) (Figure 5). Statistical analysis was performed using XLSTAT program, and the level of statistical significance was $p<0.05$. To compare individual proportions, the N-1 $\chi^{2}$ test was used according to the procedure described by Campbell (2007) and Richardson (2011). To determine confidence intervals, a method proposed by Altman (2000) was used. The $\chi^{2}$ test and Monte Carlo analysis were used to compare the proportions between the three groups, 


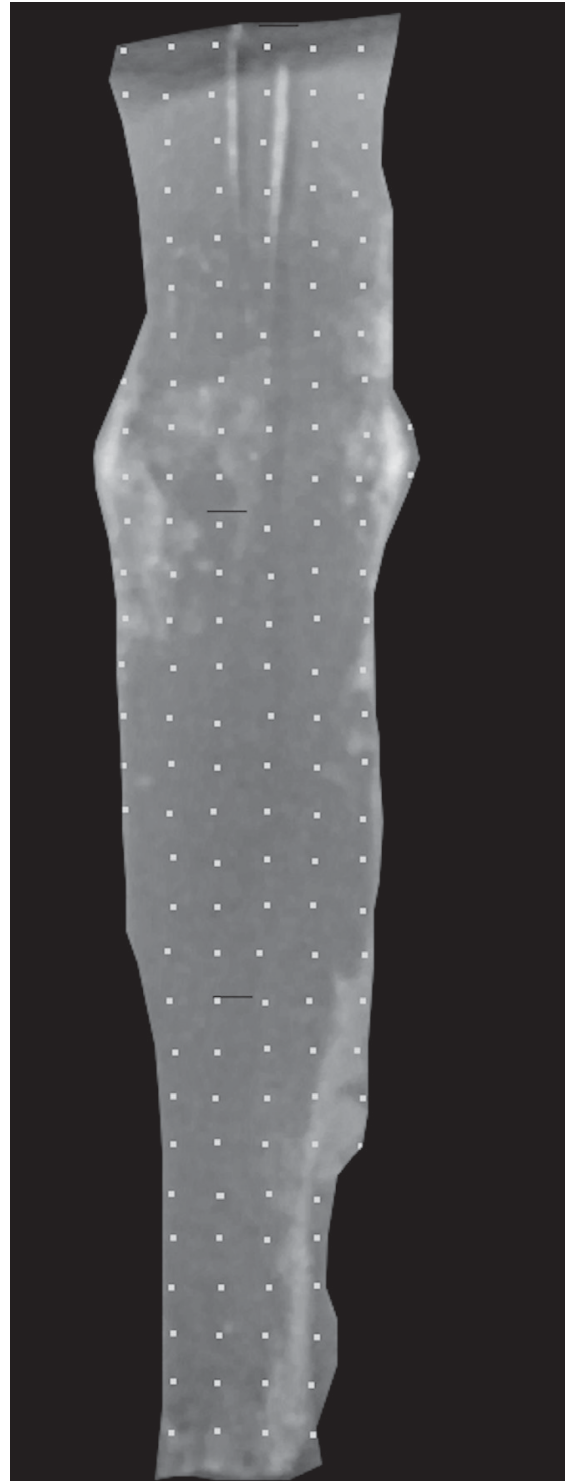

FIGURE 5. Example of canal after dressing removal from LC group, excised, and divided into three parts, including apical, middle, and coronal (white spots helped calculating squares of a crisscross pattern)

while the Marascuilo procedure was used to determine the significance between each pair of comparisons.

\section{RESULTS}

The first stage of statistical analysis was to compare whether there was any difference between the percentage of cleaned surface in wide and narrow canals depending on the root canal fragment. In the apical fragment, the percentage of cleaned surface was $12.61 \%$ in narrow and $52.12 \%$ in wide canals $(p<0.0001)$. In the middle fragment of the root, it was $36.36 \%$ in narrow and $83.14 \%$ in wide canals $(p<0.0001)$, whereas in coronal fragment of the root, it was $10.33 \%$ in narrow and $58.41 \%$ in wide canals $(p<0.0001)$ (Table 1$)$. The second phase concerned the determination of the differences between cleaned surfaces within both types of canals using the $\chi 2$ test and Monte Carlo analysis. The Monte Carlo

TABLE 1. First stage of statistical analysis was to compare whether there was any difference between the percentage of cleaned surface in wide and narrow canals depending on the root canal fragment. In apical fragment, the percentage of cleaned surface was $12.61 \%$ in narrow and $52.12 \%$ in wide canals $(p<0.0001)$. In middle fragment of the root, it was $36.36 \%$ in narrow and $83.14 \%$ in wide canals ( $p<0.0001$ ), whereas in coronal fragment of the root, it was $10.33 \%$ in narrow and $58.41 \%$ in wide canals $(p<0.0001)$

\begin{tabular}{|l|c|c|c|c|}
\hline \multicolumn{2}{|c|}{$\begin{array}{c}\text { Narrow } \\
\text { canal }\end{array}$} & Wide canal & $\begin{array}{c}\text { Difference } \\
\text { between } \\
\text { canals }\end{array}$ & p-value \\
\hline Apex & $12.6126 \%$ & $52.1246 \%$ & $39.51 \%$ & $<0.0001$ \\
\hline Middle & $36.3636 \%$ & $83.1372 \%$ & $46.77 \%$ & $<0.0001$ \\
\hline Coronal & $10.3260 \%$ & $58.4103 \%$ & $48.08 \%$ & $<0.0001$ \\
\hline \multicolumn{5}{|c|}{ Difference between canal clearance } \\
\hline
\end{tabular}

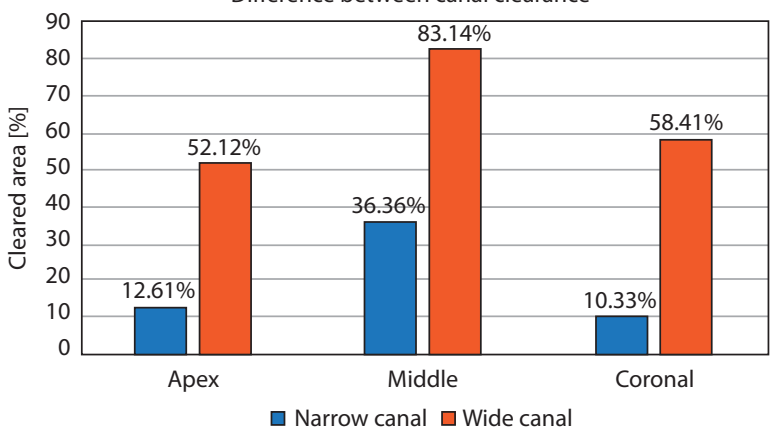

TABLE 2. Comparison of particular parts of canals from NC group. Marascuillo procedure allows comparison of all possible pairs of proportions. By applying the test, a difference is statistically significant, as its value exceeds the critical range value

\begin{tabular}{|l|c|c|c|}
\hline NC group & Value & \multicolumn{1}{c|}{ Critical value } & Significant \\
\hline $\mid p($ APEX) $-p$ (MEDIAL) $\mid$ & 0.141 & 0.106 & Yes \\
\hline $\mid p($ APEX) $-p$ (CORONAL) $\mid$ & 0.023 & 0.086 & No \\
\hline$|p(M E D I A L)-p(C O R O N A L)|$ & 0.163 & 0.082 & Yes \\
\hline
\end{tabular}

TABLE 3. Comparison of particular parts of canals from LC group. Marascuillo procedure allows comparison of all possible pairs of proportions. By applying the test, a difference is statistically significant, as its value exceeds the critical range value

\begin{tabular}{|l|c|c|c|}
\hline \multicolumn{1}{l}{ LC group } & Value & \multicolumn{1}{c|}{ Critical value } & Significant \\
\hline $\mid p$ (APEX) $-p$ (MEDIAL) $\mid$ & 0.067 & 0.086 & No \\
\hline $\mid p$ (APEX) $-p(C O R O N A L) \mid$ & 0.063 & 0.083 & No \\
\hline $\mid p$ (MEDIAL) - $p$ (CORONAL) $\mid$ & 0.130 & 0.077 & Yes \\
\hline
\end{tabular}


assessment confirmed that there was at least one group that was significantly different from the other. The final step was the comparison of groups with each other using the Marascuilo procedure, which determined the significance between individual pairs (Tables 2 and 3).

\section{DISCUSSION}

To achieve better disinfection of the root canal system, an active irrigation should be employed. This is justified by many published studies, proving that during the mechanical preparation of root canals, the contact surface of rotary files with the canal wall is about $40-45 \%[4,5]$, and assuming that the rest of canal surface can remain infected until chemical preparation is introduced. In addition, it is very important to eliminate a smear layer and also to remove an intra-canal dressing placed between endodontic visits. The most common canal dressing is calcium hydroxide [6]. Apart from its well-known benefits, calcium hydroxide is considered difficult to be completely removed from the root canal system. What is of particularly importance for the incomplete calcium hydroxide removal is that its remnants left in the canal resorb over the time and could be a source of bacterial microleakage [7]. The problem increases in cases with very wide canals. Anatomical conditions of wide root canals force clinicians to change chemo-mechanical procedure. Due to weakened root structure, the mechanical preparation is limited and the canal disinfection is based mainly on the chemical preparation of the canal. In a study comparing the effect of removing dressing from narrow canals with the use of Brush-Finisher file, a group of wide canals was created. Preliminary results confirm the difficulty in obtaining similar cleanliness of wide canal walls throughout their entire course of the procedure. The group of narrow canals was cleaned more effectively, also in the apical section, which surface is reported to be the most difficult to reach [8]. In practice, the preparation of oval canals poses a similar problem. Studies assessing the effect of disinfection or material removal from such canals indicate superiority of some instruments over the other. Self-adjusting file system (ReDent Nova, Ra'anana, Israel), files made of modified NiTi alloy, or a method of flushing with negative apical pressure, have all been described [9-12]. It could be that the proper design or specific work of the described instruments contributed to obtain better results. For example, the combination of rotary instrumentation and ultrasonic activation for 3 periods of 20 seconds each, resulted in significantly lower amounts of $\mathrm{Ca}(\mathrm{OH})_{2}$ remnants in the canal compared with sonic irrigation [13]. However, this correlates with root canal system of mesial roots of mandibular molars. To confirm their effectiveness in wide canals, a further study concerning the described project is required.

Before execution of the presented pilotage, the usage of an apical groove model was taken into consideration.
It is a standardized method used commonly in the research [10]. The created groove is prepared in the root dentine and assumed to imitate an isthmus or canal restriction, which is the most difficult site to eliminate a biofilm or endodontic material from. On the other hand, it could not be adapted for anatomies of wide canals. To bring the conditions of in vitro examination closer to clinical situation, we have also resigned from the use of simulated canals or artificial grooves in acrylic blocks. In this study, a decision was made to use digital radiographs obtained in two projections as a visualization method. It enabled to compare the amount of remained dressing in particular groups. This method was used by other researchers, e.g., to analyze the effects of root canal retreatment [14]. Conebeam computed tomography (CBCT) is another instrument used in such kind of research [15]. It is used for volumetric evaluation, however, based on particular scans. CBCT provides a volumetric assessment of samples, although it requires the use of specialized software that is common in micro-CT methods. Moreover, CBCT provides lower spatial resolution than periapical radiographs, giving various artifacts that disturb image analysis [16]. Nowadays, micro-CT technology is the best laboratory method, still quite unavailable and very expensive [17]. For the study assumption, the radiological method can be used for the comparison of tested groups.

In the literature, there is still insufficient amount of studies evaluating the effect of Brush-Finisher [18]. Its use in the group of narrow canals provided good results in removing the dressing. These results are comparable with the outcomes of other studies $[19,20]$. However, the method of evaluating the amount of residual dressing in the canals was different, therefore, the exact compilation of results requires further research.

\section{CONCLUSIONS}

The present study requires continuance and additional groups of instruments to investigate that would allow to draw appropriate conclusions. However, owing to this preliminary study, we obtained results indicating defined trends, which concern better effectiveness of dressing removal using activated irrigation with a Brush-Finisher from narrow canals than large ones. The cleanliness was achievable even within the apical part of these canals. Also, complex anatomy, which involves spacious root canal system impedes dressing removal by activated irrigation, and the usage of a Brush-Finisher in wide canals still might be insufficient or require further confirmation of compatibility.

\section{CONFLICT OF INTEREST}

The authors declare no potential conflicts of interest with respect to the research, authorship, and/or publication of this article. 


\section{References}

1. Arslan H, Akcay M, Capar ID, Saygili G, Gok T, Ertas H. An in vitro comparison of irrigation using photon-initiated photoacoustic streaming, ultrasonic, sonic and needle techniques in removing calcium hydroxide. Int Endod J 2015; 48: 246-251.

2. Türker S, Kocak M, Kocak S, Sağlam B. Comparison of calcium hydroxide removal by self-adjusting file, EndoVac, and CanalBrush agitation techniques: an in vitro study. J Conserv Dent 2013; 16: 439-443.

3. Koprowicz A, Pawlicka H, Grącka-Mańkowska J. Activated irrigation by gentlefile during root canal therapy. J Stoma 2019; 72: 34-42.

4. Krasimir H, Gateva N. Effectiveness of different root canal irrigation protocols in treatment of immature permanent teeth. MedInform 2019; 2: 1043-1052.

5. Poggio C, Dagna A, Chiesa M, Scribante A, Beltrami R, Colombo M. Effects of NiTi rotary and reciprocating instruments on debris and smear layer scores: an SEM evaluation. J Appl Biomater Funct Mater 2014; 12: 256-262.

6. Mohammadi Z, Dummer PM. Properties and applications of calcium hydroxide in endodontics and dental traumatology. Int Endod J 2011; 44: 697-730.

7. Kim S, Kim Y. Influence of calcium hydroxide intracanal medication on apical seal. Int Endod J 2002; 35: 623-628.

8. Rödig T, Hirschleb M, Zapf A, Hülsmann M. Comparison of ultrasonic irrigation and RinsEndo for the removal of calcium hydroxide and Ledermix paste from root canals. Int Endod J 2011; 44: 1155-1161.

9. De-Deus G, Souza EM, Barino B, et al. The self-adjusting file optimizes debridement quality in oval-shaped root canals. J Endod 2011; 37: 701-705.

10. Wigler R, Dvir R, Weisman A, Matalon S, Kfir A. Efficacy of $\mathrm{XP}$-endo finisher files in the removal of calcium hydroxide paste from artificial standardized grooves in the apical third of oval root canals. Int Endod J 2017: 50: 700-705.

11. Bortoluzzi EA, Carlon D Jr, Meghil MM, et al. Efficacy of 3D conforming nickel titanium rotary instruments in eliminating canal wall bacteria from oval-shaped root canals. J Dent 2015; 43: 597-604.

12. De Gregorio C, Paranjpe A, Garcia A, et al. Efficacy of irrigation systems on penetration of sodium hypochlorite to working length and to simulated uninstrumented areas in oval shaped root canals. Int Endod J 2012; 5: 475-481.

13. Wiseman A, Cox TC, Paranjpe A, Flake NM, Cohenca N, Johnson JD. Efficacy of sonic and ultrasonic activation for removal of calcium hydroxide from mesial canals of mandibular molars: a microtomographic study. J Endod 2011; 37: 235-238.

14. de Carvalho Maciel AC, Zaccaro Scelza MF. Efficacy of automated versus hand instrumentation during root canal retreatment: an ex vivo study. Int Endod J 2006; 39: 779-784.

15. Nandini S, Velmurugan N, Kandaswamy D. Removal efficiency of calcium hydroxide intracanal medicament with two calcium chelators: volumetric analysis using spiral CT, an in vitro study. J Endod 2006; 32: 1097-1101.

16. Patel S, Brown J, Semper M, Abella F, Mannocci F. European Society of Endodontology position statement: use of cone beam computed tomography in Endodontics. Int Endod J 2019; 52: 1675-1678.

17. Leoni GB, Versiani MA, Silva-Sousa YT, Bruniera JFB, Pécora JD, Sousa-Neto MD. Ex vivo evaluation of four final irrigation protocols on the removal of hard-tissue debris from the mesial root canal system of mandibular first molars. Int Endod J 2017; 50: 398-406.

18. Neelakantan P, Khan K, Li KY, Shetty H, Xi W. Effectiveness of supplementary irrigant agitation with the Finisher GF Brush on the debridement of oval root canals instrumented with the Gentlefile or nickel titanium rotary instruments. Int Endod J 2018; 51: 800-807.
19. Balvedi RPA, Versiani MA, Manna FF, Biffi JCG. A comparison of two techniques for the removal of calcium hydroxide from root canals. Int Endod J 2010; 43: 763-768.

20. Ma J, Shen Y, Yang Y, et al. In vitro study of calcium hydroxide removal from mandibular molar root canals. J Endod 2015; 41: 553-558. 